\title{
Analysis of Motivation Mechanism to Management within Junior Faculty in Universities \& Colleges
}

\author{
Fang Zhang \\ BUAA (Beijing University of Aeronautics and Astronautics) Beijing, 100083
}

\begin{abstract}
People from all walks of life are paying more and more attention to the development of the education and teaching industry which shows the importance of school management of young teachers in colleges and universities is increasingly prominent in the rapid development of the modernized social economy. The comprehensive quality and professional ethics of young teachers in colleges and universities are directly related to the development of China's higher education while effective implementation of motivation mechanisms could be instrumental in enhancing the professional ethics of them. Therefore, combining material incentive mechanisms and moral encouragement to perfect management to professional ethics can build a high-quality faculty team. This paper mainly analyzes the incentive mechanism in the management of young teachers in colleges and universities.
\end{abstract}

Keywords: Colleges and Universities; Management of Junior Teachers; Motivation Mechanism

DOI: $10.36012 /$ fhe.v1i2.1434

\section{Introduction}

I

$\mathrm{n}$ the process of college education and teaching, young teachers are the key to the college faculty and play an important role in the fields of college teaching, scientific research, social service, and cultural inheritance. In the rapid development of the new era, the young need to continuously improve their comprehensive quality and actively participate in various work which is related to sustained and steady development and beneficial to enhance the comprehensive competitive strength of colleges and universities. Basing on these ideas, this paper sets forth relevant content about motivation mechanism, analyzes the difficulties in management to young teachers, and sums up corresponding implementation strategies to support the effectiveness for management of junior faculty in universities and colleges.

\section{Relevant Contents of Motivation Mecha- nism}

\subsection{Purpose of Motivation Mechanism}

Motivation mechanism could be regarded as a continuing development mechanism that managers shall abide by the laws and regulations fundamentally then deeply analyze the value orientation and cultural environment, and strengthen the material and spiritual rewards for the managed personnel. Analyzing in terms of its nature, the motivation process belongs to the process of demands meeting. In this process, colleges and uni- versities need to fully understand the actual needs of young teachers, implement corresponding measures to stimulate the motivation of them and achieve the expected goals. In the process of professional ethics management of young teachers in colleges and universities, relevant administrative departments need to help young teachers timely update their ideas by means of incentive measures and incentives means providing support for the improvement of the moral quality of them.

\subsection{Principles}

\subsubsection{People-Oriented Management}

People-oriented management is the essential symbol of modern management of human civilization, the funda mental of professional ethics management of young teachers in colleges and universities is human management ${ }^{[1]}$. In the process of professional ethics management of young teachers in colleges and universities, managers need to establish the people-oriented concept, according to the actual needs of them to stimulate the enthusiasm and creativity to create a relaxed and pleasant working atmosphere for young faculty.

\subsubsection{Differentiated Reward}

In the process of implementing the incentive system, colleges and universities must pay attention to the diversities, according to the different levels, contributions, post types, give corresponding rewards as support, could not implement the "one-size-fits-all" model, such as all young teachers are treated equally and given the same reward regardless of their performance 
levels which could not meet the expec ted results would hit teachers which perform well. Therefore, it is necessary to carry out a combined mechanism with motivation and restraint for highlighting the differences.

\subsubsection{Fairness}

Generally, the return on one's efforts is not determined by absolute value but by the competitor. In the process of implementing motivation mechanisms, universities and colleges need to make sure fairness, justice, and openness of review in the case of unfairness. For an instance, one young teacher under the situation that he or she had never paid out anything but got the same reward as others which did work hard, in this way which would produce comparative psychology.

2.2.4 Integration of Material Rewards and Spiritual Rewards

Motivation includes two aspects, namely material reward and spiritual reward. Among them, material rewards can mobilize the enthusiasm of young teachers in colleges and universities but lack of durability, Spiritual rewards can meet the psychological needs of young teachers in colleges and universities with the characteristics of sustainability but the degree of reward is relatively weaker, which require the combination of material rewards and spiritual rewards to create a good incentive atmosphere for them.

\section{Demands of Young Faculty in University and Colleges}

\subsection{Demand for Further Development}

Development demand refers to the balance demand that the comprehensive quality and various conditions of the subject cannot adapt to the current state. In order to meet their actual needs, young teachers need to continue to study but for the relatively special working environment of them which makes the development demands of young teachers more intense that they still need to further study. During the development process of universities and colleges, many outstanding graduates choose to remain in school and they are responsible for administration and teaching supporting generally, such as professor secretary, instructor, lab tutor, etc., which do play extremely important roles. However, due to the small space for them to develop on campus, they hold a strong desire for further study hoping to improve their academic and professional level to provide support for their career development. At the same time, young full-time teachers in university and colleges often have a master degree or above but there are a large number of excellent talents around them so that fierce competition is inevitable which is hard to highlight teaching achievements and academic achievements having a strong effect on the promotion of young faculty. As a result, young teachers in colleges and universities would take advanced courses in different ways to improve their academic level.

\subsection{Demands for Entrepreneurship}

Among the young teachers in colleges and universities, there are many doctors, post-doctors and returnees who generally hope to improve their thinking and solving ability of problems and better cope with challenging work. In addition, hoping they could integrate into the existing researching institute in a team and then conduct in-depth research and exploration on their major also publish more academic articles which turn research into productivity supplying a wider space and more time for young faculty in universities and colleges and implementing flexible assessment system and motivation mechanism which reflect the entrepreneurial needs of them.

\subsection{Social Demand}

In the process of education in universities and colleges, young faculty especially those who just graduated who are in the posts of teachers and administrators they all hope to integrate into the working environment as soon as possible. In general, young teachers in colleges and universities pay more attention to the evaluation of themselves by others and after the implementation of the teaching quality evaluation system, they generally hope to be liked by students and recognized and respected by colleagues ${ }^{[2]}$.

\subsection{Material Demand}

In the development of modern society, young teachers in university and colleges pursue a noble career but they still need to face many practical problems, such as go together, starting a family, buying a home. Supporting parents and raising children, etc., which makes them live under much stress so that they have a higher strict to material demand. Additionally, under the background of deepening the reform of the socialist market economy, highly-educated young teachers pay more and more attention to their interests and pursue the perfect unity of "value of dedication and value of demand". 


\section{The Problem of Incen tive Mechanism in the Management of Young Teachers in Col- leges and Universities}

\subsection{Lack of Effectiveness in the Implementation}

In the management of young teachers in colleges and universities, colleges and universities need to implement the corresponding incentive system and give full play to the role of the incentive system. In the process of encouraging young faculty in colleges and universities, assessment is the key basis and standard. However, in this process, the evaluation system is not perfect, cause of human motivation, relationship motivation problems existing in the incentive, run into a form and could not for outstanding young teachers in scientific and reasonable assessment and evaluation which is difficult to enjoy the benefits of fair incentive, even there are a lot of young teachers in the process of formal operation tend to rely on their own, relations have motivation. In addition, in the process of assessment and evaluation, equalitarianism has emerged, leading to the phenomenon of "doing more and doing less and doing the same" in the actual work of young teachers in colleges and universities, which cannot realize the effectiveness of the incentive mechanism for young teachers.

\subsection{Lack of Pertinence and Flexibility}

Young teachers belong to a special group of teachers in colleges and universities, in the early stage of academic career, they are generally facing the survival dilemma, because of this, colleges and universities need to develop incentive systems for young teachers with diverse standards, tailored needs and flexible policies, so as to enable young teachers to adapt to the living environment as soon as possible and improve their living difficulties providing support for academic career development. Nonetheless, the reward standard is relatively single, often will take the scientific research as the focus, does not pay attention to the young teachers teaching work; Moreover, the incentive mechanism lacks certain pertinence and the incentive system tends to focus on all teachers ignoring the different needs of young teachers in special periods. In addition, in the process of assessment and evaluation of incentive mechanism, colleges and universities often implement unified standards for all teachers and fail to establish a sound incentive system according to the actual situation of them resulting in the failure of effective implementation of the incentive system for young teachers in colleges and universities.

\section{The Implementation Strategy of Incentive Mechanism in the Management of Young Faculty in Colleges and Universities}

\subsection{Improve the Work Ethics of Young Faculty}

In the management process of young teachers in colleges and universities, colleges and universities need to integrate material incentives and spiritual incentives. After obtaining material and spiritual incentives young teachers in colleges and universities tend to pursue higher demands having a strong demand for self-realization value. At this time, university administrators need to do a good job of ideological guidance to guide young teachers to improve their moral level and professional ability. For example, colleges and universities can implement the school management model of school affairs for outstanding young teachers, listen to and adopt the suggestions of young teachers for their concerns, and make them feel the realization of their self-worth. It is also necessary to strengthen the ideological guidance of young teachers in colleges and universities so that they can actively improve their comprehensive quality and professional ethics and ensure the smooth implementation of college education and teaching.

\subsection{Give Full Play to Young Teachers in the Incen-} tive Mechanism

In the management of young teachers in colleges and universities, the main components of encouragement are the subject, object, and means of encouragement. The young teacher is the key, which is not only the object of receiving encouragement but also the subject of improving their own consciousness. In the traditional incentive mechanism, in the process of formulating the incentive strategy and implementing the incentive tactics, colleges and universities do not pay attention to the self-demand consciousness and self-management consciousness of young teachers, implement the traditional administrative imperative incentive means generally ignoring the actual needs of young teachers in colleges and universities. In order to improve this situation effectively, young teachers in colleges and universities need to give full play to their main role, respond to policymakers according to their actual needs, listen to their own voice in time giving full play to the role of policies. In addition, more opportunities should 
be provided for young teachers with low job satisfaction. In the communication process between relevant departments, colleges and secondary departments of the school, we should help young teachers to alleviate their bad emotions, timely find out the problems in the incentive mechanism, formulate the incentive system reasonably, according to the actual needs of young teachers to ease the relationship with young teachers.

\subsection{Ensure the Timeliness and Stability of the Mo- tivation}

In order to give full play to the guiding role of the incentive mechanism, colleges and universities need to ensure the timeliness and stability of incentives and improve the overall level of the management of young teachers, administrators also need to dig into the talents of young teachers and constantly improve their comprehensive quality. At the same time, the management departments should realize the importance of the management work of young teachers in colleges and universities, coordinate with each other, and improve the limitation of the leadership will. In the design and operation of the incentive mechanism, the administrative departments of colleges and universities cannot manage according to the work experience but they should strengthen the exchange and communication with young teachers in colleges and universities, understand the actual needs of young teachers in colleges and universities, and formulate the corresponding incentive mechanism on the basis of that. And coordinate the incentive resources of colleges and universities to give full play to the role of the incentive resources of young teachers in colleges and universities. Making corresponding incentive mechanism schedule arranges incentive mechanism funds reasonably, on the basis of ensuring adequate resources, implementing long-term incentive of young teachers to ensure the timeliness and stability of incentives.

\section{Conclusion}

To sum up, in order to improve the professional ethics of young teachers in colleges and universities, colleges and universities need to establish a sound motivation mechanism with material and spiritual integrated. During the implementation of various incentive systems, colleges and universities should follow the relevant principles according to their actual conditions and the characteristics of young teachers so as to ensure the flexibility and variability of the incentive mechanism and give full play to the role of the incentive mechanism improving the comprehensive quality of young teachers in colleges and universities.

\section{References}

[1] Wang Yu Zhi, Zhao Lin Guo. Innovation Analysis of Salary Incentive Mechanism for Young Teachers in Colleges and Universities [J].Heilongjiang Researches on Higher Education, 2017(11):101-103.

[2] Zhao Gui Gui, Meng Qing Chun. Exploration of the Motivation Mechanism of Young Teachers in Private Colleges and Universities [J]. Journal of Shandong College of Agricultural Engineering,2016,33(4):61-62.

[3] Lu Pei Yan, Liu Mei Xian, Lu Mei Xi. Research on the Cultivation of Young Teachers in Colleges and Universities Based on Career Management [J]. Journal of Nanjing University of Science and Technology (Social Science Edition), 2018,31(3):79-83.

[4] Youth Fund Project of Ministry of Education, A comparative study on the academic productivity of young teachers in colleges and universities -- based on the comparison between "overseas returnees' doctor" and "local doctor", Serial Number: 16YJC880099 